\title{
For debate: advanced bleeding control potentially saves lives in armed forces and should be considered
}

\author{
Boudewijn L S Borger van der Burg, ${ }^{\circledR} 1$ P Keijzers, ${ }^{2}$ T T C F van Dongen, ${ }^{\circledR 1,3}$ \\ O J F van Waes, ${ }^{4} \mathrm{R}$ Hoencamp ${ }^{1,3,4,5}$
}

${ }^{1}$ Surgery, Alrijne Ziekenhuis locatie Leiderdorp, Leiderdorp, The Netherlands

${ }^{2}$ Surgery, Medisch Spectrum

Twente, Enschede, The

Netherlands

${ }^{3}$ Defense Healthcare

Department, Ministry of

Defence, Utrecht, The Netherlands

${ }^{4}$ Trauma Research Unit Dept. of Surgery, Erasmus MC, University Medical Center Rotterdam Rotterdam, The Netherlands ${ }^{5}$ Leiden University Medical Centre, Leiden, The Netherlands

Correspondence to Boudewijn L S Borger van der Burg, Alrijne Zorggroep, Leiderdorp 2353GA, The Netherlands; blsborgervanderburg@alrijne.nl

Received 15 April 2019 Revised 16 May 2019 Accepted 16 May 2019

Check for updates

(C) Author(s) (or their employer(s)) 2019. No commercial re-use. See rights and permissions. Published by BMJ.

\begin{tabular}{|l|}
\hline To cite: Borger van der \\
Burg BLS, Keijzers P, van \\
Dongen TTCF, et al. \\
$J$ R Army Med Corps Epub \\
ahead of print: [please \\
include Day Month Year]. \\
doi:10.1136/ \\
jramc-2019-001231 \\
\hline
\end{tabular}

\begin{abstract}
Introduction Advanced bleeding control options for truncal and junctional haemorrhage including resuscitative endovascular balloon occlusion of the aorta (REBOA) have been used in managing catastrophic bleeding. The primary aim is to report on potential indications for advanced bleeding control in combat casualties during the Dutch deployment in Uruzgan, Afghanistan, between August 2006 and August 2010. The secondary aim is to report on training methods for advanced bleeding control in (para)medical personnel.
\end{abstract}

Methods The trauma registry from the Dutch role 2 enhanced medical treatment facility at Tarin Kowt, Uruzgan, Afghanistan, was used to analyse patients who sustained a battle injury with major haemorrhage. Furthermore, a comprehensive search was performed on training (para)medical personnel in advanced bleeding control.

Results There were 212 possible indications for advanced bleeding control with mortality of $28.8 \%$ (61/212). These possible indications consisted of $1.9 \%$ (4/212) junctional lower extremity injuries with a $75 \%$ (3/4) mortality rate, 59\% (125/212) visceral vascular injuries with a mortality rate of $12.5 \%$ (26/125). The junctional and visceral injuries $(n=129)$ were all potential indications for advanced bleeding control options, such as REBOA. Further 39.2\% (83/212) casualties with central thoracic or neck injuries had a mortality rate of $38.6 \%$ (32/83). Based on an Abbreviated Injury Scale chest or abdomen score $\geq 461$ indications for advanced bleeding control were identified. A 24-hour average of 8.8 packets of red blood cells, 4.2 packets of plasma and 1.9 packets of platelets was used to prevent exsanguination. The total out-of-hospital survival rate was 64\% (39/61).

Conclusion Retrospective analysis revealed 212 potential indications for advanced bleeding control with a mortality of $28.8 \%$ (61/212). Advanced bleeding control, such as REBOA, might have improved survival in approximately 61 of 212 casualties. Advanced bleeding control could be used as an adjunct to improve outcomes in major truncal or junctional haemorrhage in prehospital, remote settings and implementation should be considered. Vascular access training and REBOA placement for (para) medical military personnel should be explored in future research.

\section{INTRODUCTION}

Controlling catastrophic bleeding is the major life-saving skill in trauma and vascular surgery. In catastrophic bleeding cases advanced bleeding options for truncal and junctional haemorrhage include wound clamps, injectable haemostatic sponges, Foley catheter balloon tamponade, pelvic circumferential stabilisers, resuscitative thoracotomy, intra-abdominal gas insufflation, intra-abdominal self-expanding foam, junctional and truncal tourniquets and resuscitative endovascular balloon occlusion of the aorta (REBOA). ${ }^{1}$ Although REBOA has been used as part of the endovascular and hybrid trauma and bleeding management concept in patients with non-compressible truncal and junctional injuries involving massive haemorrhage, implementation of REBOA in civilian or military setting for combat casualties has not been widely adopted. ${ }^{2-4}$ In 2012, Eastridge et al reviewed US battlefield fatalities (2001-2011) and classified $24.3 \%(n=976)$ as potentially survivable, with fatal injuries predominantly related to haemorrhage. ${ }^{5}$ The lag in implementation of advanced bleeding control options such as REBOA could be secondary to a possible underestimation of the potential indications for advanced bleeding control, or the lack of skills in first responders.

The primary aim of this paper is to report on the potential indications for advanced bleeding control options in combat casualties during the Dutch deployment in Uruzgan, Afghanistan, between 2006 and 2010. The secondary aim is to report on possible training methods for advanced bleeding control such as vascular access and REBOA placement, in medical and paramedical personnel to improve outcome after major haemorrhage.

\section{METHODS}

The trauma registry from the Dutch role 2 enhanced medical treatment facility (R2E MTF) at the multinational base Tarin Kowt, Uruzgan, Afghanistan, was used to identify and analyse patients who sustained a battle injury with major haemorrhage during the Dutch deployment between August 2006 and August 2010. We selected severe pelvic/ junctional/femoral injuries with an Abbreviated Injury Scale (AIS) score $\geq 4$ for this analysis. Casualties with extremity injuries scoring $\geq 4$ on the AIS are likely to sustain severe to critical bleeding. Haemorrhage control using a tourniquet is often not adequate in these severe injuries, often being a mangled extremity or a traumatic amputation well above the knee or at the pelvic level. A second analysis was performed using the data of the combined battlefield casualties and military blood bank database. The Abbreviated Injury Scale (AIS) and (New) Injury Severity Score (N)ISS, ${ }^{6-8}$ combined with the administration of packed blood products, were used to optimise the analysis for potential REBOA indications. 


\begin{tabular}{lcc}
\hline $\begin{array}{l}\text { Table 1A Potential indication for advanced bleeding control/ } \\
\text { REBOA—bleeding sites }\end{array}$ & \multicolumn{1}{l}{ S } & Survival, $\mathbf{n}(\%)$ \\
\hline Bleeding site & 4 & $3(25)$ \\
\hline Junctional lower extremity & 125 & $99(79.2)$ \\
Visceral vascular & 83 & $51(61.4)$ \\
Central thoracic or neck & 212 & $153(72.1)$ \\
\hline Total &
\end{tabular}

REBOA, resuscitative endovascular balloon occlusion of the aorta.

Statistical analyses were performed using the Statistical Package for the Social Sciences (SPSS, V.24, IBM). Furthermore, a comprehensive search was performed on the subject of training medical and paramedical personnel in advanced bleeding control options, such as vascular access and REBOA placement.

\section{RESULTS}

Dutch role 2 trauma registry data

During the Dutch deployment to Afghanistan (2006-2010) the R2E MTF treated 194 casualties with 307 major haemorrhage injuries. There was an average of 1.6 major bleeding sites per casualty. ${ }^{9}$ van Dongen et al analysed potential indications for the use of advanced bleeding control options, such as REBOA, during the deployment of the Dutch Armed Forces in Afghanistan. ${ }^{10}$ All injuries with major truncal haemorrhage, sustained during the deployment to Afghanistan 2006-2010, were identified and analysed whether they could fit the criteria for use of advanced bleeding control options.

There were in total 212 potential indications for advanced bleeding control in our cohort with mortality of $28.8 \%(61 / 212)$ (Table 1A). These potential indications consisted of $1.9 \%$ $(4 / 212)$ junctional lower extremity injuries with a $75 \%(3 / 4)$ mortality rate and 59\% (125/212) visceral vascular injuries of which $12.5 \%(26 / 125)$ casualties did not survive the injury. The junctional and visceral injuries $(n=129)$ were all potential indications for advanced bleeding control options, such as REBOA. Further 39.2\% (83/212) casualties with central thoracic or neck injuries had a mortality rate of $38.6 \%$ (32/83). Of the 83 casualties with a central thoracic or neck injury, 11 had associated haemorrhage from neck injuries. In total, 61 patients died of which three were a result of neck injury.

\section{Potential indications for advanced bleeding control based on} the AIS and administration of blood products

Casualties with an AIS chest or abdomen score $\geq 4$, indicating a severe or critical injury, were identified as potential indication for advanced bleeding control, including REBOA. These results are demonstrated in Tables 1B,C and show 61 indications for advanced bleeding control based on AIS score $\geq 4$. A 24-hour average of 8.8 packets of red blood cells (RBC), 4.2 packets of plasma and 1.9 packets of platelets was used to prevent exsanguination. The total out-of-hospital survival rate was $64 \%(39 / 61)$.

\section{DISCUSSION}

Retrospective analysis of the Dutch deployment to Afghanistan (2006-2010) revealed 212 possible indications for advanced bleeding control with a mortality of $28.8 \%$ (61/212). Clinical outcome might have improved in approximately 212 casualties when these severe injuries were treated with advanced bleeding control techniques, such as REBOA. Detailed analysis of 61 casualties revealed a high percentage of casualties $(29.3 \%)$ that needed an average of almost nine packed RBCs during the first 24 hours of resuscitation with a mortality rate of approximately $40 \%$. Although tourniquets are useful in preventing exsanguination of a peripheral haemorrhage site, truncal and junctional bleeding sites are more difficult to control. ${ }^{11} 12$ van Oostendorp et $a l^{1}$ reviewed available prehospital options for controlling life-threatening truncal and junctional haemorrhage. There are currently multiple treatment options such as wound clamps, injectable haemostatic sponges, pelvic circumferential stabilisers, resuscitative thoracotomy, REBOA, Foley catheter balloon tamponade, intra-abdominal gas insufflation, intra-abdominal self-expanding foam, junctional and truncal tourniquets. These options can be combined as advanced hybrid options in traditional open surgery to prevent exsanguination. Future research should focus on the use of these adjuncts in civilian and military austere environments. Besides devices like the aortic clamp, junctional tourniquet and foam, REBOA has already been used in the earliest phases of prehospital care and in military setting. ${ }^{13-15}$ The pioneering use of this haemorrhage control adjunct in the prehospital phase, despite early promising results, has not been widely adopted. ${ }^{15}{ }^{16}$ In civilian setting, Thabouillot et al have evaluated trauma patients registered in the Paris Fire Brigade emergency medical system with bleeding of supposedly abdominal and/or pelvic and/or junctional origin, uncontrolled haemorrhagic shock or cardiac arrest with attempted resuscitation. ${ }^{17}$ They concluded that $3.2 \%$ would have been candidates for REBOA and they believe that this intervention should be available in the prehospital setting. Barnard et al tried to identify the number of patients from England and Wales (2012-2013) using the Trauma Audit and Research Network-NHS England and Wales trauma database registry, in whom REBOA may have reasonably been used. They found that $0.055 \%$ of all trauma patients had an indication for REBOA with an overall mortality of $32 \% .^{18}$

In military setting, Eastridge et al performed an analysis of the incidence and causes of potentially preventable deaths among US combat fatalities. All battlefield fatalities (2001-2011) were reviewed and analysed, $87.3 \%$ of all mortality occurred in the pre-MTF environment. Of the pre-MTF deaths, $75.7 \%$ $(n=3040)$ were classified as non-survivable and 24.3\% $(n=976)$ were deemed potentially survivable. The injury or physiological focus of potentially survivable acute mortality was largely associated with haemorrhage (90.9\%). The site of lethal haemorrhage was truncal (67.3\%), followed by junctional $(19.2 \%)$ and peripheral extremity $(13.5 \%)$ haemorrhage. ${ }^{5}$ This has led to

\begin{tabular}{lllllll}
\hline \multicolumn{2}{l}{ Table 1B } & Potential indication for advanced bleeding control/REBOA-injury severity & & & \\
\hline Indication & $\mathbf{n}$ & ISS mean (SD) & ISS median (IQR) & NISS mean (SD) & NISS median (IQR) & Survival, $\mathbf{n}(\%)$ \\
\hline AIS chest $\geq 4$ & 14 & $24.6(9.3)$ & $25(17-25)$ & $29.8(10.4)$ & $29(23-36)$ & $10(71)$ \\
\hline AIS abdomen $\geq 4$ & 34 & $21.8(7.8)$ & $17.5(16-26)$ & $29.5(8.3)$ & $32(24-34)$ & $19(56)$ \\
AIS extremity $\geq 4$ & 15 & $21.2(6.8)$ & $16(16-26)$ & $29.1(7.5)$ & $26(25-34)$ & $11(73)$ \\
Total & $61^{*}$ & $21.5(6.9)$ & $18(16-25)$ & $29.0(8.1)$ & $29(25-34)$ & $39(64)$ \\
\hline
\end{tabular}

*Two patients had combined AIS chest and AIS abdomen $\geq 4$.

AIS, Abbreviated Injury Scale; ISS, Injury Severity Score; NISS, New Injury Severity Score; REBOA, resuscitative endovascular balloon occlusion of the aorta. 
Table 1C Potential indication for advanced bleeding control/REBOA—administration of blood products

\begin{tabular}{lcccllll}
\hline Indication & $\begin{array}{l}\mathrm{RBC} / 24 \text { hours } \\
\text { mean }(\mathrm{SD})\end{array}$ & $\begin{array}{l}\mathrm{RBC} / 24 \text { hours } \\
\text { median (IQR) }\end{array}$ & $\begin{array}{l}\geq 6 \mathrm{RBC} / 24 \text { hours } \\
(\%)\end{array}$ & $\begin{array}{l}\text { Plasma/24 hours } \\
\text { mean (SD) }\end{array}$ & $\begin{array}{l}\text { Plasma/24 hours } \\
\text { median (IQR) }\end{array}$ & $\begin{array}{l}\text { Platelets/24 } \\
\text { hours mean (SD) }\end{array}$ & $\begin{array}{l}\text { Platelets/24 hours } \\
\text { median (IQR) }\end{array}$ \\
\hline AIS chest $\geq 4(\mathrm{n}=14)$ & $6.4(4.7)$ & $4.5(2-11)$ & $6(43)$ & $3.1(3.3)$ & $2(0-6)$ & $1.4(1.6)$ & $0.5(0-3)$ \\
AlS abdomen $\geq 4(\mathrm{n}=34)$ & $9.1(6.5)$ & $8.5(4-12)$ & $24(71)$ & $4.2(3.9)$ & $3.5(1-7)$ & $2.0(1.9)$ & $2(0-3)$ \\
AIS extremity $\geq 4(\mathrm{n}=15)$ & $11.2(9.4)$ & $10(4-16)$ & $10(67)$ & $5.5(5.6)$ & $5(0-7)$ & $2.1(1.8)$ & $1(0-3)$ \\
Total $\left(\mathrm{n}=61^{*}\right)$ & $8.8(7.2)$ & $8(4-12)$ & $38(63)$ & $4.2(4.3)$ & $3(1-7)$ & $1.9(1.8)$ & $2(0-3)$ \\
\hline
\end{tabular}

*Two patients had combined AIS chest and AIS abdomen $\geq 4$.

AIS, Abbreviated Injury Scale; RBC, red blood cell; REBOA, resuscitative endovascular balloon occlusion of the aorta.

improvements in Tactical Combat Casualty Care guidelines. ${ }^{19} 20$ In 2014, Morrison et al analysed severely injured UK combat casualties and concluded that 1 in 5 severely injured UK combat casualties have a focus of haemorrhage in the abdomen or pelvic junctional region potentially amenable to REBOA deployment. ${ }^{21}$ Recently, Joseph et al published a nationwide analysis of REBOA in civilian trauma patients. A case-controlled retrospective analysis of the 2015-1026 American College of Surgeons data set containing 593818 patients compared 140 patients in the REBOA group with 280 matched patients. They concluded that patients in the REBOA group had a higher mortality rate compared with the matched non-REBOA patients. Joseph et al conclude that there is a need for a concerted effort to clearly define when and in which patient population REBOA has benefit. $^{22}$

Preventing exsanguination in military victims in pre-MTF setting involves extensive training programmes and readily available resources. Borger van der Burg et al recently published two papers on vascular access and REBOA training in personnel with limited or no prior endovascular experience (residents, (military) trauma surgeons, Special Forces medics, combat nurses and military non-surgeon physicians). These studies showed that a comprehensive theoretical and practical training programme can be used for percutaneous femoral access and REBOA placement training of personnel without prior ultrasound or endovascular experience. ${ }^{23} 24$ These findings are supported by a similar study by Pasley et al, in which it is stated that independent duty military medical technicians are able to learn and perform REBOA correctly and rapidly, but that emphasis on vascular access training is important. ${ }^{25}$ Redman and Ross report on a transportable central-perfused cadaver model suitable for training in the battlefield environment on all tactical combat casualty care procedures including REBOA. ${ }^{26}$ Using this model in different austere settings, Ross and Redman ${ }^{27}$ tested two military emergency medicine physicians with no prior endovascular surgery exposure on vascular access and REBOA placement. Successful placement was accomplished in $86 \%$ of the models and percutaneous access was successful 54\% of the time. They conclude that, with proper training, non-surgical providers can properly place REBOA catheters in austere prehospital settings at speeds.

There are limitations to this study. The data from the registry are retrospective and did not clearly distinguish between femoral and junctional injuries. However, based on the high transfusion rates and ISS, it was decided that these injuries were not manageable with regularly available tourniquets and needed advanced bleeding control techniques. Also, from the thoracic injuries, 11 had associated neck injuries in which REBOA would not have an added value. Furthermore, the exact location of bleeding in truncal injuries could not be ascertained retrospectively. When truncal injuries cause a major bleeding above the left subclavian artery, haemorrhage control with REBOA would be ineffective. However, in these injuries other advanced bleeding control measures, for instance, the use of Foley catheter balloon tamponade, could potentially have improved outcome. In a worst-case scenario (when all truncal injuries were above the left subclavian artery), REBOA would be potentially life-saving in only visceral and junctional injuries, being 29 of 129 major bleeding injuries. Another major limitation is that major bleeding is not exclusively associated with arterial bleeding. Therefore, REBOA should be labelled as an adjunct besides other more effective bleeding control measures in venous bleedings.

Achieving vascular access in a haemodynamically unstable patient is challenging. Also, the appropriate means of verifying the adequate position of the occlusion balloon are often absent in the field. Nevertheless, especially in remote and austere environments, the extraction times are longer and more unpredictable than in urban settings. Attempting to achieve haemorrhagic control with advanced bleeding control adjuncts, such as REBOA, is therefore certainly justifiable. Implementation of advanced bleeding control adjuncts, such as REBOA, should be considered in the military.

\section{CONCLUSION}

Retrospective analysis of the Dutch deployment to Afghanistan (2006-2010) revealed 212 potential indications for advanced bleeding control with a mortality of $28.8 \%$ (61/212). Advanced bleeding control, such as REBOA, might have improved survival in approximately 61 of 212 major haemorrhage casualties. Advanced bleeding control could be used as an adjunct to improve outcomes in major truncal or junctional haemorrhage in a prehospital setting, especially in a remote environment, and implementation should be considered. Vascular access training and REBOA placement for medical and paramedical military personnel should be explored in future research.

Correction notice This article has been corrected since it was published Online First. The affiliations have been updated.

Contributors BBvdB, TvD and RH prepared the study. TvD performed the statistical analyses. BBvdB, TvD and RH prepared the manuscript. TvD prepared the tables. $B B v d B, T v D, P K, O v W$ and RH contributed to the final version of the paper.

Funding The authors have not declared a specific grant for this research from any funding agency in the public, commercial or not-for-profit sectors.

Disclaimer The opinions or assertions contained herein are the private views of the authors and are not to be construed as official or reflecting the views of the Department of Defence or Dutch government. Several authors are employees of the Dutch government.

Competing interests None declared.

Patient consent for publication Not required.

Ethics approval This study was conducted under a protocol reviewed and approved by the Dutch Ministry of Defence (MoD).

Provenance and peer review Not commissioned; externally peer reviewed. Data sharing statement Data are available upon reasonable request. 


\section{REFERENCES}

1 van Oostendorp SE, Tan ECTH, Geeraedts LMG. Prehospital control of life-threatening truncal and junctional haemorrhage is the ultimate challenge in optimizing trauma care; a review of treatment options and their applicability in the civilian trauma setting. Scand I Trauma Resusc Emerg Med 2016:24.

2 Stannard A, Eliason JL, Rasmussen TE. Resuscitative endovascular balloon occlusion of the aorta (REBOA) as an adjunct for hemorrhagic shock. J Trauma 2011;71:1869-72

3 Hörer TM, Skoog P, Pirouzram A, et al. A small case series of aortic balloon occlusion in trauma: lessons learned from its use in ruptured abdominal aortic aneurysms and a brief review. Eur J Trauma Emerg Surg 2016:42:585-92.

4 Borger van der Burg BLS, van Dongen TTCF, Morrison JJ, et al. A systematic review and meta-analysis of the use of resuscitative endovascular balloon occlusion of the aorta in the management of major exsanguination. Eur J Trauma Emerg Surg 2018;44:535-50.

5 Eastridge BJ, Mabry RL, Seguin P, et al. Death on the battlefield (2001-2011): implications for the future of combat casualty care. J Trauma Acute Care Surg 2012;73(6 Suppl 5):S431-7.

6 Copes WS, Champion HR, Sacco WJ, et al. The injury severity Score revisited. J Trauma 1988;28:69-77.

7 Gennarelli TA. The Abbreviated Injury Scale (A/S). Des Plaines: American Association for Automotive Medicine, 1985.

8 Lavoie A, Moore L, LeSage N, et al. The new injury severity Score: a more accurate predictor of in-hospital mortality than the injury severity Score. J Trauma 2004;56:1312-20.

9 van Dongen TTCF, Idenburg FJ, Tan ECTH, et al. Combat related vascular injuries: Dutch experiences from a role 2 MTf in Afghanistan. Injury 2016;47:94-8.

10 van Dongen T, Borger van der Burg BLS, Hoencamp R. Combat related truncal major hemorrhage: what about EVTM and REBOA? European. Valencia, Spain: Congress of Trauma and Emergency Surgery, 2018.

11 Passos E, Dingley B, Smith A, et al. Tourniquet use for peripheral vascular injuries in the civilian setting. Injury 2014;45:573-7.

12 Shackelford SA, Butler FK, Kragh JF, et al. Optimizing the use of limb tourniquets in tactical combat casualty care: TCCC guidelines change 14-02. J Spec Oper Med 2015;15:17-31.

13 Lyon M, Johnson D, Gordon R. Use of a novel abdominal aortic and junctional tourniquet to reduce or eliminate flow in the brachial and popliteal arteries in human subjects. Prehosp Emerg Care 2015;19:405-8.
14 Sadek S, Lockey DJ, Lendrum RA, et al. Resuscitative endovascular balloon occlusion of the aorta (REBOA) in the pre-hospital setting: an additional resuscitation option for uncontrolled catastrophic haemorrhage. Resuscitation 2016;107:135-8.

15 Manley JD, Mitchell BJ, DuBose JJ, et al. A modern case series of resuscitative endovascular balloon occlusion of the aorta (REBOA) in an out-of-hospital, combat casualty care setting. J Spec Oper Med 2017;17:1-8.

16 Reva VA, Hörer TM, Makhnovskiy Al, et al. Field and en route resuscitative endovascular occlusion of the aorta: a feasible military reality? J Trauma Acute Care Surg 2017;83(1 Suppl 1):S170-S176.

17 Thabouillot O, Bertho K, Rozenberg E, et al. How many patients could benefit from REBOA in prehospital care? A retrospective study of patients rescued by the doctors of the Paris fire Brigade. J R Army Med Corps 2018;164:267-70.

18 Barnard EBG, Morrison JJ, Madureira RM, et al. Resuscitative endovascular balloon occlusion of the aorta (REBOA): a population based gap analysis of trauma patients in England and Wales. Emerg Med J 2015;32:926-32.

19 Kotwal RS, Butler FK, Montgomery HR, et al. The Tactical Combat Casualty Care Casualty Card TCCC Guidelines ? Proposed Change 1301. J Spec Oper Med 2013;13:82-7

20 Pasley J, Cannon J, Glaser J, et al. Resuscitative endovascular balloon occlusion of the aorta (REBOA) for hemorrhagic shock, 2018: 382017.

21 Morrison JJ, Ross JD, Rasmussen TE, et al. Resuscitative endovascular balloon occlusion of the aorta: a gap analysis of severely injured UK combat casualties. Shock 2014;41:388-93.

22 Borger van der Burg BLS, Hörer TM, Eefting D, et al. Vascular access training for REBOA placement: a feasibility study in a live tissue-simulator hybrid porcine model. $J$ R Army Med Corps 2019;165.

23 Joseph B, Zeeshan M, Sakran JV, et al. Nationwide analysis of resuscitative endovascular balloon occlusion of the aorta in civilian trauma. JAMA Surg 2019. doi:10.1001/jamasurg.2019.0096. [Epub ahead of print: 20 Mar 2019].

24 Borger van der Burg BLS, Maayen RCLA, van Dongen TTCF, et al. Feasibility study vascular access and REBOA placement: from zero to hero. J Spec Oper Med 2018;18.

25 Pasley JD, Teeter WA, Gamble WB, et al. Bringing resuscitative endovascular balloon occlusion of the aorta (REBOA) closer to the point of injury. J Spec Oper Med 2018;18:33-6.

26 Redman TT, Ross EM. A novel Expeditionary perfused cadaver model for trauma training in the out-of-hospital setting. J Emerg Med 2018;55:383-9.

27 Ross EM, Redman TT. Feasibility and proposed training pathway for Austere application of resuscitative balloon occlusion of the aorta. J Spec Oper Med 2018;18:37-43. 